\title{
Analysis of Factors Affecting Air Kerma Area Product Obtained during Uterine Artery Embolization Procedures Using Logistic Regression
}

\author{
Khaled Soliman ${ }^{1, \oplus}$ Ahmed Almutairi ${ }^{2} \quad$ Murdhi AlHarbi ${ }^{2} \quad$ Khaleel Almutairi ${ }^{2}$ \\ Turky Almutairi² Mousa Bakkari
}

${ }^{1}$ Department of Medical Physics, Prince Sultan Military Medical City, Riyadh, Saudi Arabia

${ }^{2}$ Department of Radiodiagnostic and Medical Imaging, Prince Sultan Military Medical City, Riyadh, Saudi Arabia

\begin{abstract}
Address for correspondence Khaled Soliman, PhD, DABMP, Department of Medical Physics, Prince Sultan Military Medical City, P. O. Box 7897 (B-94), Riyadh 11159, Saudi Arabia (e-mail: khaledsoliman61@gmail.com).
\end{abstract}

Indian J Radiol Imaging 2021;31:265-269.

\begin{abstract}
Purpose Uterine artery embolization (UAE) is a common interventional radiology procedure used in medicine; the procedure is safe but there is always a concern regarding radiation dose received by the patient. The aim of this study was to use multivariable logistic regression analysis (MLRA) to study a certain number of independent prognostic variables believed to provide an estimate of the likelihood of obtaining a high kerma area product $\left(P_{\mathrm{KA}}\right)$ at the end of the procedure.

Method Radiation dose indices registered by the angiographic system structured dose report, the total fluoroscopy time (FT), the patient' body mass index (BMI), the number of images taken during the procedures (IMGS), and the performing physician experience (EXPER) were used to drive a logistic regression model (LRM).

Results The LRM found was: Logit $\left(P_{K A}\right)=-6.1525+0.0416(F T)+0.1028$ (IMGS) + 0.1675 (BMI) -0.1012 (EXPER). The prediction accuracy of the LRM was assessed using receiver operating characteristic (ROC) curve; by calculating the area under the curve

Keywords

- air kerma

- logistic regression

- predictive variables

- uterine artery embolization

- radiation dose

(AUC), we found $A \cup C=0.7896$, with optimal ROC point of $0.3261,0.8036$.

Conclusion The suggested LRM seems to indicate that patients with higher BMI, have taken longer FT, acquired higher IMGS and the procedure done by a less experienced performing physician is more susceptible to receive a higher $P_{\mathrm{KA}}$ at the end. The proposed LRM is useful in predicting the occurrence of higher radiation exposure interventions and can be used in patients' radiation dose optimization strategies during UAE procedures.
\end{abstract}

\section{Introduction}

Uterine artery embolization (UAE) is a minimal invasive procedure that requires fluoroscopic and angiographic imaging and this causes a concern regarding the radiation dose received by the patient during the intervention. It is known

published online July $28,, 2021$
DOI https://doi.org/ $10.1055 / \mathrm{s}-0041-1733814$ ISSN 0971-3026 that angiographic imaging systems can deliver a significant amount of radiation to the patient's skin; therefore, radiation dose monitoring is required. ${ }^{1}$ We have reviewed the radiation dose metrics available from the angiographic system for 102 UAE procedures performed on the system during the past year 2019. Along with the dosimetric metrics we have
(C) 2021. Indian Radiological Association.

This is an open access article published by Thieme under the terms of the Creative Commons Attribution-NonDerivative-NonCommercial-License, permitting copying and reproduction so long as the original work is given appropriate credit. Contents may not be used for commercial purposes, or adapted, remixed, transformed or built upon. (https://creativecommons.org/licenses/by-nc-nd/4.0/).

Thieme Medical and Scientific Publishers Private Ltd. A-12, Second Floor, Sector -2, NOIDA -201301, India 
also included the body mass index (BMI) and the interventional radiologist experience (EXPER) to the variables that will be analyzed.

Multivariable logistic regression (MLR) analysis has been widely used as a method to identify prognostic factors affecting medical treatments outcome. ${ }^{2}$ The aim of this study was to analyze radiation dose-related metrics available from the angiographic system and from the radiology information system (RIS) and to use MLR to estimate the occurrence of high radiation dose procedures.

\section{Methods}

\section{Patient Characteristics}

In this study we have retrospectively collected from the angiographic system registered dose report and from the (RIS) data concerning 102 patients who underwent UAE procedures in 2019. Radiation dose indicators such as, the fluoroscopy time (FT) in minutes, the cumulative kerma area product $\left(P_{\mathrm{KA}}\right)$ in Gy $\mathrm{cm}^{2}$, the cumulative reference air kerma $\left(K_{\mathrm{a}, \mathrm{r}}\right)$ in $\mathrm{mGy}$, the number of images taken during the procedure (IMGS), and the calculated patient body mass index (BMI) were collected. We also noted for each patient the experience of the performing physician in the form of total number of performed UAE procedures in the variable (EXPER). - Table 1 has the summary of the patients' data used in this work. This retrospective study was approved by the institution's research ethics committee.

\section{Imaging Equipment}

We used a biplane system C-arm with flat detector angiography, AXIOM Artis dBA (Siemens, Erlangen, Germany).

\section{Logistic Regression Analysis}

A binary logistic regression model (LRM) was calculated using variables that may predict the level of cumulated $P_{\mathrm{KA}}$ at the end of the procedure. It is known that $P_{\mathrm{KA}}$ is related to the risk of exposure to radiation.

$P_{\mathrm{KA}}$ is the binary outcome variable used in the analysis. High $P_{\mathrm{KA}}$ levels are assigned the value of 1 and routine $P_{\mathrm{KA}}$ levels will be assigned the value 0 . The LRM will have the following form:

$$
Y=\ln (\text { odds }[\text { event }])=\beta_{0}+\beta_{1} x_{1}+\beta_{2} x_{2}+\ldots \ldots \ldots \ldots+\beta_{n} x_{n}(1)
$$

In Eq. (1) the variable $Y$ is $\log$ (naturel) of the odds of the event under consideration. In our case the event will be the occurrence of high $P_{\mathrm{KA}}$ procedure. The $\beta$ s are the coefficients of the regression calculated by the model and $n$ is the number of predictive variables. The odds ratios are the exponential of the coefficients and will be given by:

$$
\text { Odds ratios }=\operatorname{Exp}(\beta)
$$

\section{Statistical Analysis}

The DAP values for 102 patients were dichotomized into two groups $>300 \mathrm{~Gy} \mathrm{~cm} \mathrm{~cm}^{2}$ and $\leq 300 \mathrm{~Gy} \mathrm{~cm}^{2}$, the first group is considered as high radiation dose procedure (HRDP) and the second as routine radiation dose procedure.

The choice of $300 \mathrm{~Gy} \mathrm{~cm}^{2}$ was based on the American Society of Vascular Interventional Radiology. ${ }^{3}$ They recommended alert levels to be displayed on the Angiographic system during the procedure, as to alert the surgeon that a DAP value of $300 \mathrm{~Gy} \mathrm{~cm}^{2}$ has been reached. Furthermore $300 \mathrm{~Gy} \mathrm{~cm}^{2}$ is considered an appropriate indicator for substantial radiation dose levels for most interventional radiology procedures. ${ }^{4}$

One of the objectives of this study was to identify the independent variables which are able to estimate HRDP group during UAE and to propose a LRM for the prediction of HRDP.

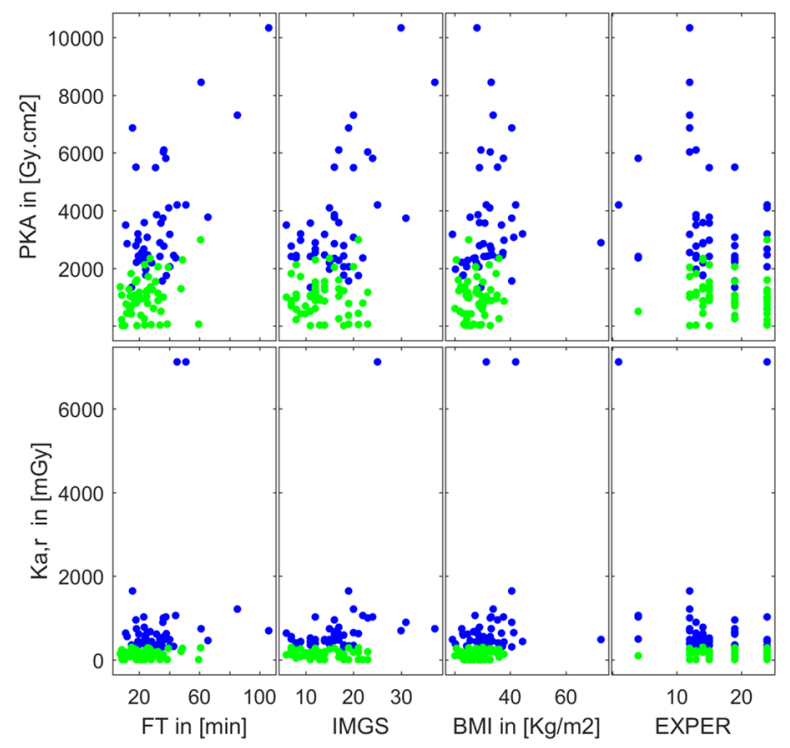

Fig. 1 Scatter plots matrix showing $K_{\mathrm{a}, \mathrm{r}}$ and $P_{\mathrm{KA}}$ as function of FT, IMGS, BMI, and EXPER, respectively. The dark blue dots are for the

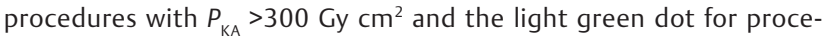
dures with $P_{\mathrm{KA}} \leq 300 \mathrm{~Gy} \mathrm{~cm}^{2}$. BMI, body mass index; $\mathrm{FT}$, fluoroscopy time; EXPER, experience; IMGS, images.

Table 1 Summary of 102 patients' data and their associated radiation dose metrics

\begin{tabular}{|l|l|l|l|l|l|l|}
\hline & FT $(\min )$ & IMGS & BMI $\left(\mathrm{kg} / \mathrm{m}^{2}\right)$ & EXPER & $P_{\mathrm{KA}}\left(G y \mathrm{~cm}^{2}\right)$ & $K_{\mathrm{a}, \mathrm{r}}(\mathrm{mGy})$ \\
\hline Mean & 28 & 14.9 & 30.0 & 16.5 & 480 & 2,140 \\
\hline Minimum & 7.3 & 6.0 & 19.3 & 1 & 0.46 & 9.14 \\
\hline Maximum & 105.9 & 37 & 72.6 & 24 & 7,125 & 10,340 \\
\hline Coefficient of variation & 15.7 & 5.8 & 6.9 & 5.3 & 991 & 1,882 \\
\hline
\end{tabular}

BMI, body mass index; FT, fluoroscopy time; EXPER, experience; IMGS, images. 

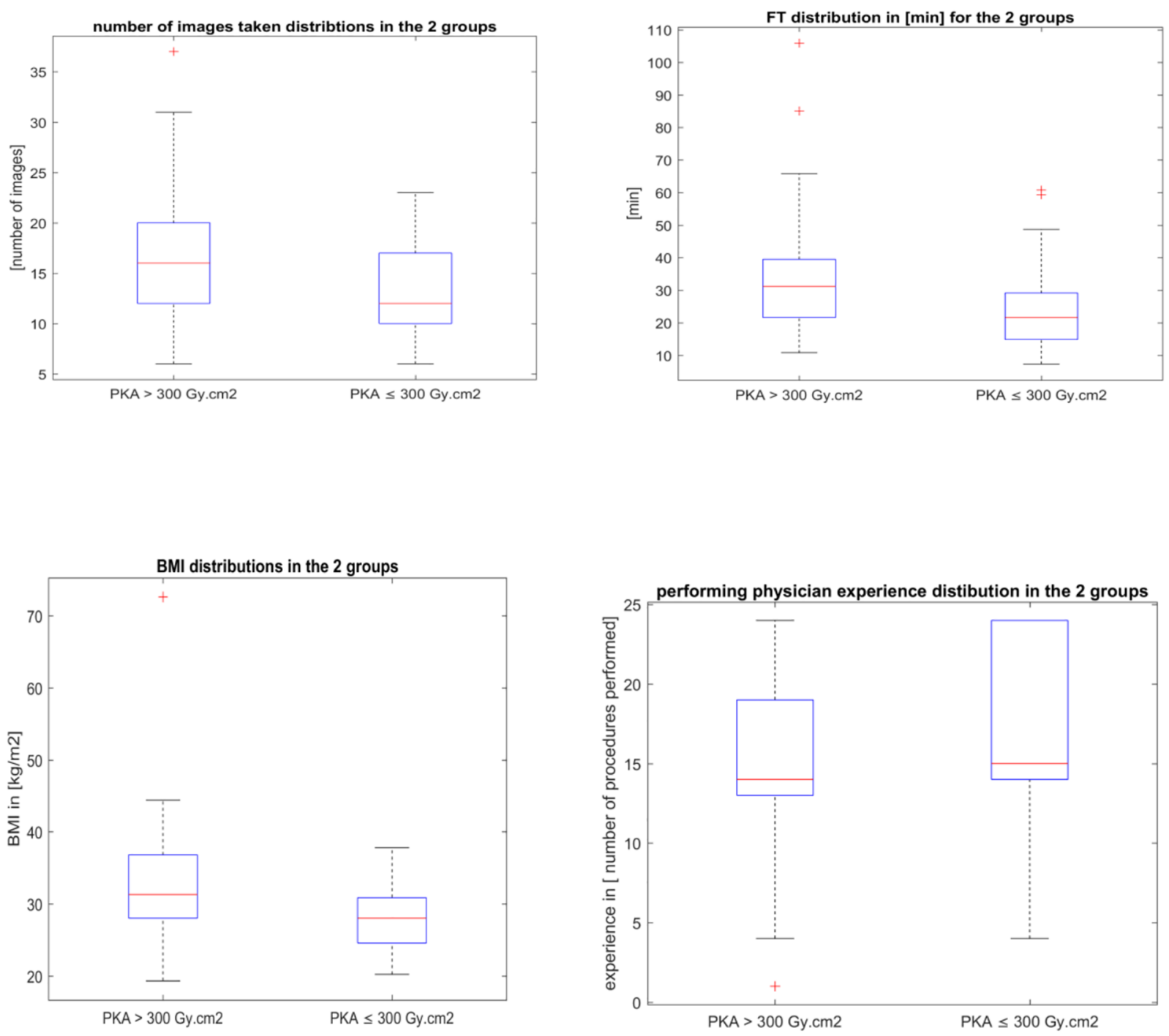

Fig. 2 Boxplots showing the four predicting variables distribution for the two dependent variable categories: $P_{\mathrm{KA}}>300 \mathrm{~Gy} \mathrm{~cm}^{2}$ and $P_{\mathrm{KA}}$ $\leq 300 \mathrm{~Gy} \mathrm{~cm}^{2}$.

-Fig. 2 is showing the data distribution in the form of boxplots.

The statistical analysis was performed using Matlab (R2016b) statistics and machine learning toolbox (Natick, United States). A p-value of $(<0.05)$ was considered statistically significant.

\section{Results}

As expected, a linear regression relationship was found between the cumulative air kerma measured at the reference point $\left(K_{\mathrm{a}, \mathrm{r}}\right)$ and the cumulated kerma area product $\left(P_{\mathrm{KA}}\right)$, therefore $K_{\mathrm{a}, \mathrm{r}}$ was excluded from the list of the predicting independent variables. Fig. 1 contains scatter plot matrix of the Ka,r and PKA as function of FT, IMGS, BMI, and EXPER variables.

\section{Binary Logistic Regression Model}

The degree of significance of four variables: FT, IMGS, BMI, and EXPER was examined. - Table 2 has the summary of the results. The obtained LRM with four predictors (variables) FT, IMGS, BMI and EXPER is given by the Eq. (3) below:

$$
\begin{gathered}
\operatorname{Logit}\left(P_{\mathrm{KA}}\right)=-6.1525+0.0416(\mathrm{FT})+0.1028(\mathrm{IMGS})+ \\
0.1675(\mathrm{BMI})-0.1012(\mathrm{EXPER})
\end{gathered}
$$

These results show that an increase of one unit of FT (1 minute) will have an increase of $4.16 \%$ in the cumulative $P_{\mathrm{KA}}$, similarly an increase of one unit in the number of images taken will have an increase of $10.2 \%$ in the $P_{\mathrm{KA}}$ value, an increase of 1 unit in the BMI $\left(1 \mathrm{~kg} / \mathrm{m}^{2}\right)$ will have an increase of $16.75 \%$ in the cumulative $P_{\mathrm{KA}}$ and an increase of 1 unit in the variable EXPER will have a decrease in the total $P_{\mathrm{KA}}$ value by $10.12 \%$; this variable is working in the advantage of lower $P_{\mathrm{KA}}$ value as opposed to the other three variables that all working in the advantage of obtaining a larger $P_{\mathrm{KA}}$ value.

The model was tested for goodness of fit with the DAP data using the area (AUC) under the ROC. The AUC was equal to 0.7896 with optimal ROC point coordinate of $(0.3261$, 
Table 2 Results of the multivariable logistic regression analysis for all the variables that may be related to the occurrence of high radiation exposure UAE procedure

\begin{tabular}{|c|c|c|c|c|}
\hline$p$-Value & OR (95\% Cl) & OR & $B$ & Variables \\
\hline 0.0014 & & & 6.1525 & Intercept \\
\hline 0.0508 & $(1.000-1.087)$ & 1.042 & 0.0416 & FT \\
\hline 0.0643 & $(0.994-1.236)$ & 1.108 & 0.1028 & IMGS \\
\hline 0.0008 & $(1.072-1.304)$ & 1.182 & 0.1675 & BMI \\
\hline 0.0485 & (0.817-0.999) & 0.904 & 0.1012 & EXPER \\
\hline
\end{tabular}

Abbreviations: $B$, regression coefficients; OR, odds ratio; $p$, the $p$-value.

Table 3 Some of the reported PKA in the literature

\begin{tabular}{|l|l|l|l|l|}
\hline Author & Year & $\left.\boldsymbol{P}_{\mathrm{KA}}(\mathrm{Gy} \mathrm{cm})^{2}\right)$ & $K_{\mathrm{a}, \mathrm{r}}(\mathrm{Gy})$ & $\mathbf{n}$ \\
\hline Miller et al & 2009 & 392 & & 90 \\
\hline Vano et al & 2009 & 236 & & 56 \\
\hline Ruiz-Cruces et al & 2016 & 214 & & \\
\hline Durrani et al & 2016 & $437(267)^{\mathrm{a}}$ & & \\
\hline Kohlbrenner et al & 2017 & $438(175)^{\mathrm{a}}$ & & \\
\hline Schernthaner et al & 2018 & $527(146)^{\mathrm{a}}$ & & 100 \\
\hline This study & 2020 & 347 & 2.1 & \\
\hline
\end{tabular}

aThe values in parentheses are the values obtained after applying imaging system optimization.

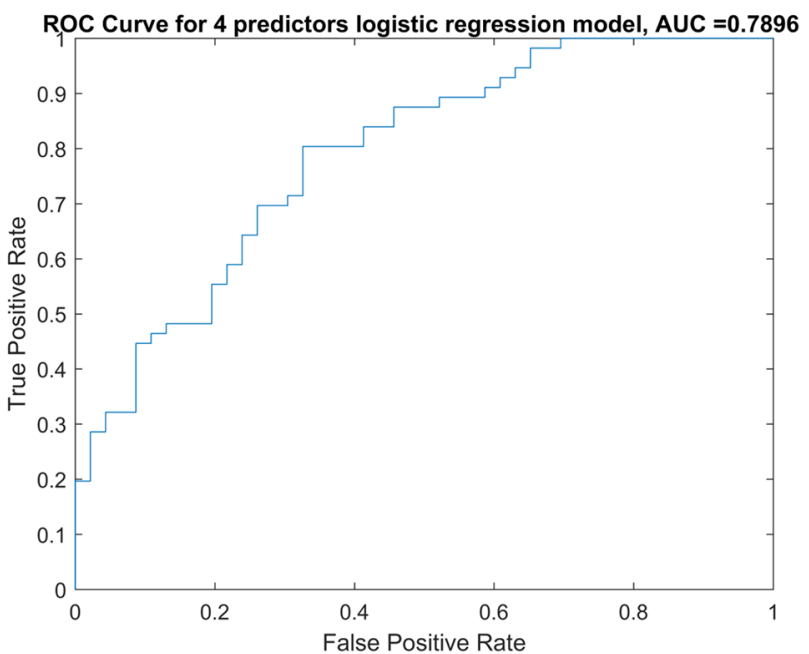

Fig. 3 The ROC curve for the proposed four predicative variables logistic regression model. ROC, receiver operating characteristic.

0.8036). - Fig. 3 shows the ROC for the four variables predictive model. The optimal ROC point seems to indicate a false positive rate of $32.6 \%$ and a true positive rate of $70.3 \%$ for the predictive model obtained.

\section{Discussion}

Comparing radiation dose values and dosimetric quantities among published studies is very difficult because the procedures identification are not standardized and also their complexity varies considerably and there is no classification for procedures in accordance with their respective complexity level yet. ${ }^{5}$ Therefore there is always a need to perform regular local clinical dose audits. In this work we have analyzed available patient dose-related metrics with the aim of identifying the metrics or variables that affect the patient radiation exposure the most represented by the kerma area product during UAE.

\section{Kerma Area Products during UAE}

There are several published studies reporting radiation dose assessments and dose reduction and optimization techniques. ${ }^{6-11}$ The reported values of $P_{\mathrm{KA}}$ are in - Table 3 . In this study we have found a median $P_{\mathrm{KA}}$ value of $347 \mathrm{~Gy} \mathrm{~cm}^{2}$ for 102 UAE procedures conducted in 2019.

\section{Suggested Reference Levels}

The recommended dose reference level (DRL) for UAE was set at $450 \mathrm{~Gy} \mathrm{~cm}^{2}$ and the reported 75th percentile $P_{\mathrm{KA}}$ from the radiation doses in interventional radiology procedures study (RAD-IR) data was $392 \mathrm{~Gy} \mathrm{~cm}^{2}{ }^{6}$

Procedures with DAP values above $300 \mathrm{~Gy} \mathrm{~cm}^{2}$ should be optimized if possible. A recent study suggests using a DAP value of $50 \mathrm{~Gy} \mathrm{~cm}^{2}$ as target value for UAE procedures. In this study the authors suggested strategies for reducing radiation exposure during UAE; the strategies included: optimized source image and object image distances, avoidance of magnification, use of tight collimation, use of road-mapping, avoidance of oblique projections, use of pulsed fluoroscopy with low images per second, use of low frame rates, use of last-image-hold, and avoid three-dimensional rotational angiography. ${ }^{12}$ 
The use of optimization strategies will reduce the radiation dose received by the patients as well as the staff performing the procedure especially in cases expected to lead to a higher than usual radiation dose like for obese patients. ${ }^{13}$

A recent study had concluded that during UAE procedures, BMI had the greatest impact on the cumulated $K_{\mathrm{a}, \mathrm{r}}$ and has a substantial impact on the risk of radiation-induced skin injury even without prolonged FT. ${ }^{14}$

\section{Performing Physician Experience}

The effect of interventional radiologist experience on FT and $K_{\mathrm{a}, \mathrm{r}}$ was studied, and the conclusion was: although there was no nonsignificant trend for shorter screening times with experience, technical success and safety were not compromised with appropriate consultant supervision, which illustrates a safe construct for IR training. This is important and reassuring information for patients undergoing a procedure in a training unit. ${ }^{15}$

This conclusion is not in agreement with this study since we have found a statistically significant correlation between the operator experience and the reported $P_{\mathrm{KA}}(p=0.0485)$.

\section{Complexity Level of the Procedure}

Another study suggested after analyzing 56 UAE procedures, to include procedure complexity levels to facilitate clinical audits and proper use of DRLs in terms of $P_{\mathrm{KA}}$ for patient dose optimization in interventional radiology. They recommend DRLs of 167, 214, and $613 \mathrm{~Gy} \mathrm{~cm}^{2}$ for simple, medium, and complex index UAE procedures, respectively. Statistical analyses ( $r$ Pearson and ANOVA test) identified significant correlations between the complexity score and patient dose (KAP) for all of the procedures $(F<0.05) .{ }^{8}$

\section{Limitations}

This retrospective study analyzed data from one medical center during 1 year and included 102 patients; the study was on one imaging system only. The study did not include information about the complexity level of the procedure. The level of complexity was reported in the literature to have an effect on the DRLs. Expanding the study to include more than one imaging system, multiple medical centers, and procedure complexity level, when possible, will improve the accuracy of the proposed predictive LRM. Furthermore, a follow-up study aiming at validating the proposed model using other patients' data is recommended.

\section{Conclusion}

In conclusion, the results of this retrospective study suggest that a UAE procedure having a cumulative DAP higher than $300 \mathrm{~Gy} \mathrm{~cm}^{2}$ is likely to occur in procedures having patients with higher BMI values, have taken longer FT, acquired higher IMGS, and were accomplished by a less experienced performing physician.

The proposed LRM is useful in predicting the occurrence of higher radiation exposure interventions and can be used in patients' radiation dose optimization strategies during UAE procedures.

\section{Funding \\ None.}

\section{Conflict of Interest}

None declared.

\section{References}

1 Balter S, Hopewell JW, Miller DL, Wagner LK, Zelefsky MJ. Fluoroscopically guided interventional procedures: a review of radiation effects on patients' skin and hair. Radiology 2010;254(2):326-341

2 McCarthy CJ, Kilcoyne A, Li X, et al. Radiation dose and risk estimates of CT-guided percutaneous liver ablations and factors associated with dose reduction. Cardiovasc Intervent Radiol 2018;41(12):1935-1942

3 Stecker MS, Balter S, Towbin RB, et al. SIR Safety and Health Committee; CIRSE Standards of Practice Committee. Guidelines for patient radiation dose management. J Vasc Interv Radiol 2009;20(suppl 7):S263-S273

4 Balter S, Miller DL. Patient skin reactions from interventional fluoroscopy procedures. AJR Am J Roentgenol 2014;202(4):W335-42

5 Dauer LT, Thornton R, Erdi Y, et al. Estimating radiation doses to the skin from interventional radiology procedures for a patient population with cancer. J Vasc Interv Radiol 2009;20(6):782-788, quiz 789

6 Miller DL, Kwon D, Bonavia GH. Reference levels for patient radiation doses in interventional radiology: proposed initial values for U.S. practice. Radiology 2009;253(3):753-764

7 Vano E, Sanchez R, Fernandez JM, et al. Patient dose reference levels for interventional radiology: a national approach. Cardiovasc Intervent Radiol 2009;32(1):19-24

8 Ruiz-Cruces R, Vano E, Carrera-Magariño F, et al. Diagnostic reference levels and complexity indices in interventional radiology: a national programme. Eur Radiol 2016;26(12):4268-4276

9 Kohlbrenner R, Kolli KP, Taylor AG, et al. Radiation dose reduction during uterine fibroid embolization using an optimized imaging platform. J Vasc Interv Radiol 2017;28(8):11291135.e1

10 Durrani RJ, Fischman AM, van der Bom IM, et al. Radiation dose reduction utilizing noise reduction technology during uterine artery embolization: a pilot study. Clin Imaging 2016;40(3):378-381

11 Schernthaner RE, Haroun RR, Nguyen S, et al. Characteristics of a new X-ray imaging system for interventional procedures: improved image quality and reduced radiation dose. Cardiovasc Intervent Radiol 2018;41(3):502-508

12 Scheurig-Muenkler C, Powerski MJ, Mueller JC, Kroencke TJ. Radiation exposure during uterine artery embolization: effective measures to minimize dose to the patient. Cardiovasc Intervent Radiol 2015;38(3):613-622

13 Shah A, Das P, Subkovas E, Buch AN, Rees M, Bellamy C. Radiation dose during coronary angiogram: relation to body mass index. Heart Lung Circ 2015;24(1):21-25

14 Lacayo EA, Khera SS, Spies JB. Impact of patient and procedure-related factors on radiation exposure from uterine artery embolization. Cardiovasc Intervent Radiol 2020;43(1):120-126

15 Das R, Lucatelli P, Wang H, Belli AM. Identifying the learning curve for uterine artery embolisation in an interventional radiological training unit. Cardiovasc Intervent Radiol 2015;38(4):871-877 